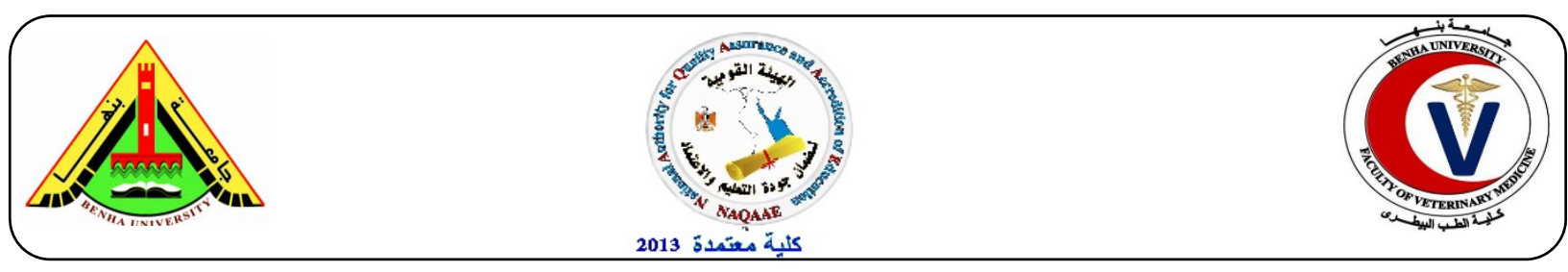

\title{
Prevalence of E.Coli in diseased chickens with its antibiogram pattern.
}

\author{
Ashraf A. Abd EI Tawab ${ }^{1}$, Ahmed M. Ammar' ${ }^{2}$ Soad A. Nasef ${ }^{3}$, Reem M. Reda ${ }^{3}$ \\ ${ }^{1}$ Department of Bacteriology, Immunology and Mycology, Faculty of Veterinary Medicine, Benha \\ University. ${ }^{2}$ Department of Bacteriology, Immunology and Mycology, Faculty of Veterinary Medicine, \\ Zagazig University. ${ }^{3}$ Reference Laboratories for Veterinary Quality Control on Poultry Production, \\ Dokki, Giza.
}

\begin{abstract}
A B S T R A C T
Prevalence of E.coli among poultry farms was investigated in these studies, which cover different provinces in Egypt through examination of 400 chicken samples using standard methods for isolation and identification of E.coli. The result showed presence of E.coli among imported chicks in rate $44 \%$ and from local broiler chickens about $75 \%$. The incidence of E.coli in on day old living diseased chicks was(58.3), while the incidence of E.coli from local broiler chickens was (71\%) from living diseased chickens and about (83\%) from freshly dead chickens These serotype of E.coli were O63, O103, O125, O158, O44. Antibiogram pattern test indicated the highest rate of resistant against tetracycline group where about $80 \%$ followed by the $2 \beta$-Lactam antibiotic (73.3\%), erythromycin about $63.3 \%$ of tested isolate were resistant, florfenicol about $53.3 \%$ were resistant, gentamycin was about $46.6 \%$ were resistance, finally ciprofloxacin about $40 \%$ of tested isolate were resistant by using disc diffusion method.
\end{abstract}

Keywords: E.coli, Diseased chickens, Antibiogram pattern.

(http://www.bvmj.bu.edu.eg)

conference issue

(BVMJ-28(2): 224-230, 2015)

\section{INTRODUCTION}

E .coli is a member of the family Enterobacteriaceae, which may constitute a great hazard to poultry industry causing high mortality, loss of weight and reduction of egg production (Bandyopadhay and Dhawedkar, 1984). E.coli infection is one of the serious problems that cause a great threat to the profitability of birds' enterprises all over the word. Although E.coli is a normal inhabitant of the intestinal tract of birds, under the influence of predisposing factors, like inadequate and faulty ventilation, overcrowding, hunger, thirst, extremes of temperatures and low vitality, high mortality during rearing, reduced weight gain and condemnation of birds at the time of slaughter (Kaulet al., 1992). Avian colibacillosis is a complex syndrome characterized by multiple organ lesions with air sacculitis and associated pericarditis, perihepatitis and peritonitis being most typical (Ewers et al., 2003). The main clinical signs of naturally infected chicks with E.coli are reported as depression, loss of appetite, tendency to huddle respiratory distress, reduction of weight gain, droped wing, closed eyes, cyanosis and labored breathing (Barnes, 1994). Antimicrobial therapy is an important tool in reducing both the incidence and mortality associated with avian colibacillosis. However, resistance to existing antimicrobials is widespread and of concern to poultry veterinarians (Cloud et al., 1985; Amara et al., 1995 and Blanco et al., 1998). This increasing resistance has received considerable national and international attention. The aim of the current work was establish to record the prevalence of E.coli infection in chickens 
and the antibiogram pattern against the isolated strains.

\section{MATERIAL AND METHODS}

\subsection{Chicken samples}

A total of 400 chickens samples were collected300from imported chicks and 100 from local broiler chickens). The samples were collected from different organ (liver, yolk sac, lungs and bone marrow) from different age (one day old-over one day old).

2.2. Detection of E.coli by conventional method: it was done according to Quinn et al. (2002)

\subsubsection{Selective enrichment of E.coli}

Each sample was inoculated separately into buffer peptone water and incubated at $37^{\circ} \mathrm{C}$ for $18 \mathrm{hrs} 2 \mathrm{hrs}$ under aerobic condition.

\subsubsection{Colonization of E.coli on selective differential solid media}

A loopful from the broth of each sample was streaked onto MacConkey's agar and Eosin Methylene blue agar. The inoculated plates were incubated at $37^{\circ} \mathrm{C}$ for 24 hours. Suspected E.coli colonies were purified and kept for further identification.

\subsubsection{Identification of suspected E.coli colonies}

It was performed according to Quinn et al., (2002): On MacConkey's agar and Eosin Methylene blue agar (EMB).

\subsubsection{Microscopic examination}

Gram's stain was prepared and used as described by (Cruickshank et al. 1975) for morphological study.

\subsubsection{Biochemical Identification}

According to Quinn et al. (2002) including Indole reaction, Methyl red test, Voges
Proskauer test, Citrate utilization test, Catales test, Sugar fermentation test, Oxidase test, Triple sugar iron and Christener's urea agar test.

\subsubsection{Serological identification of E.coli (Edwards and Ewing (1972)}

Isolated strains were serotyped in animal health research institute, Dokki, Giza using: Polyvalent and monovalent diagnostic E.coli antisera.

\subsection{Antibacterial sensitivity test}

The disk diffusion technique was applied according to (Cruickshank et al., 1975).Seven type of antibiotics from different groups of antibiotics (ciprofloxacin, florfenicol, erythromycin, gentamycin, amoxicillin and ampicillin and tetracycline was used (The interpretation of inhibition zones of tested culture was according to NCCLS, 2002).

\section{RESULTS}

\subsection{Incidence of E.coli infection in chicken}

Examination of imported baby chicks revealed that detection of E.coli in $44 \%$ from 300 examined samples while in local broiler chickens revealed that detection of E.coli in $75 \%$ from 100 examined samples table (1).

Table (1) Incidence of E.coli recovered from examined chickens:

\begin{tabular}{lccc}
\hline Sample & $\begin{array}{c}\text { No. of } \\
\text { sample }\end{array}$ & $\begin{array}{c}\text { No. of } \\
\text { positive }\end{array}$ & percentage \\
\hline $\begin{array}{l}\text { Imported } \\
\text { chicks }\end{array}$ & 300 & 133 & $44 \%$ \\
$\begin{array}{l}\text { Local } \\
\text { chickens* }\end{array}$ & 100 & 75 & $75 \%$ \\
Total & 400 & 208 & $52 \%$ \\
\hline
\end{tabular}

* Broiler 
Table (2) Incidence of E.coli In different organs of one day old chick (imported chicks)

\begin{tabular}{|c|c|c|c|c|c|c|c|c|c|c|c|}
\hline \multirow{2}{*}{ Sample } & \multirow{2}{*}{$\begin{array}{c}\text { No of } \\
\text { examined }\end{array}$} & \multicolumn{8}{|c|}{ Different organs } & \multicolumn{2}{|c|}{$\begin{array}{c}\text { Incidence of } \\
\text { E.coli }\end{array}$} \\
\hline & & liver & $\%$ & lung & $\%$ & heart & $\%$ & $\begin{array}{l}\text { Yolk } \\
\text { sac }\end{array}$ & $\%$ & total & $\%$ \\
\hline $\begin{array}{l}\text { Living } \\
\text { diseased }\end{array}$ & 180 & 50 & 27.7 & 10 & 5.5 & 25 & 13.8 & 20 & 11.1 & 105 & 58.3 \\
\hline Freshly dead & 120 & 15 & 12.5 & 4 & 3.3 & 6 & 5 & 3 & 2.5 & 28 & 23.3 \\
\hline Total & 300 & 65 & 21.6 & 14 & 4.6 & 31 & 10 & 2.3 & 7.6 & 133 & 44.3 \\
\hline
\end{tabular}

Table (3) Incidence of E.coli in different organs of over one week old chickens (local broiler chickens):

\begin{tabular}{|c|c|c|c|c|c|c|c|c|c|c|c|}
\hline \multirow{2}{*}{ Sample } & \multirow{2}{*}{$\begin{array}{c}\text { No of } \\
\text { examined }\end{array}$} & \multicolumn{8}{|c|}{ Different organs } & \multicolumn{2}{|c|}{$\begin{array}{c}\text { Incidence of } \\
\text { E.coli }\end{array}$} \\
\hline & & liver & $\%$ & lung & $\%$ & heart & $\%$ & $\begin{array}{l}\text { Bone } \\
\text { marrow }\end{array}$ & $\%$ & total & $\%$ \\
\hline $\begin{array}{l}\text { Living } \\
\text { diseased }\end{array}$ & 70 & 15 & 21 & 5 & 7 & 10 & 14.2 & 20 & 28 & 50 & 71 \\
\hline Freshly dead & 30 & 7 & 23 & 3 & 10 & 5 & 16.6 & 10 & 33 & 25 & 83 \\
\hline Total & 100 & 22 & 22 & 8 & 8 & 15 & 15 & 30 & 30 & 75 & 75 \\
\hline
\end{tabular}

\subsection{Incidence of E.coli In different organs of one day old chicks (imported chicks)}

The internal organs of each chick were examined by bacteriological examination to determine the incidence of E.coli in each chick organ table (2). The incidence of E.coli in one day old living diseased chicks was $(58.3 \%)$ while in freshly dead chicks it was $(23.3 \%)$. The highest percentage of organ isolation was obtained from liver it was about $21.6 \%$.

\subsection{Incidence of E.coli in different organs of over one week old chicken (broiler chicken)}

The incidence of E.coli in over one week old living diseased chickens was $(71 \%)$ while in freshly dead chickens it was (83\%). The highest percentage of organ isolation were obtained from bone marrow was about $30 \%$ from 100 sample (28\%), table (3).

\subsection{Serotyping of E.coli isolates recovered from chicken samples}

The hundred and eight of E.coli strains recovered from different organs of chickens relieved that 158 strain can be identified serologically they belonged to different serogroups. The most commonly detected E.coli serogroups were O44, O158, O125, O103, O63, while50 strain is not typed, table (4).

\subsection{Antibiotic sensitivity of E.coli strains}

The highest rate of resistance was shown against tetracycline group of antibiotic where about $80 \%$ of isolate were resistant followed by the $2 \beta$-Lactam antibiotic (amoxicillin and ampicillin) (73.3\%) followed by erythromycin about $63.3 \%$ of tested isolate were resistant, florfenicol about $53.3 \%$ were resistant, gentamycin is about $46.6 \%$ were resistance, finally ciprofloxacin about $40 \%$ of tested isolate were resistant ( table 5).

Table (4) Serotyping of E.coli isolates and its percentage

\begin{tabular}{lcc}
\hline E.coli serotype & No of isolate & $\%$ \\
\hline O44 & 18 & 11.3 \\
O158 & 18 & $11.3 \%$ \\
O114 & 16 & $10 \%$ \\
O91 & 14 & $8.8 \%$ \\
O125 & 12 & $7.5 \%$ \\
O63 & 12 & $7.5 \%$ \\
O55 & 1 & $.36 \%$ \\
O151 & 1 & .3 \\
O124 & 2 & 1.2 \\
\hline
\end{tabular}




\begin{tabular}{lcc}
\hline O128 & 15 & 9.4 \\
O26 & 6 & 3.7 \\
O1 & 1 & .3 \\
O144 & 1 & .3 \\
O159 & 12 & 7.5 \\
O103 & 15 & 9.4 \\
O6 & 8 & 3.7 \\
O166 & 1 & .3 \\
O142 & 5 & 3.1 \\
Typable & 158 & 75.9 \\
Not serotype & 50 & 24 \\
\hline Total & 208 & $100 \%$ \\
\hline
\end{tabular}

Table (5) Result of antibiotics resistance of E.coli by disc diffusion method

\begin{tabular}{llllllll}
\hline Isolate & $\mathrm{G}$ & $\mathrm{E}$ & $\mathrm{T}$ & $\mathrm{C}$ & $\mathrm{A}$ & $\begin{array}{l}\mathrm{A} \\
\mathrm{M}\end{array}$ & $\begin{array}{l}\mathrm{FF} \\
\mathrm{C}\end{array}$ \\
\hline Sensitive & 10 & 7 & 4 & 1 & 4 & 5 & 9 \\
& & & & 0 & & & \\
Intermitte & 6 & 4 & 2 & 8 & 4 & 3 & 5 \\
$\mathrm{nt}$ & & & & & & & \\
Resistanc & 14 & 19 & 2 & 1 & 22 & 22 & 16 \\
$\mathrm{e}$ & & & 4 & 2 & & & \\
$\% *$ & 46. & 63. & 8 & 4 & 73. & 73. & 53. \\
& 6 & 3 & 0 & 0 & 3 & 3 & 3 \\
\hline
\end{tabular}

* Resistance percent, G: gentamycin, E: erythromycin, T: tetracycline, C: ciprofloxacin, A: ampicillin, FFC: florfenicol, AM: amoxcicilin

\section{DISCUSSION}

In the present study, E.coli was detected after pre-enrichment on BPW. Then inoculated direct on agar medium (MacConky agar, VRBL and EMB agar), Typical colonies on TSA were used for further morphological and biochemical identification (catalase, oxidase, indole, methyl red, vogasproskour, citrate, TSI, LI and urea) (Swayne et al., 1998). The typical E.coli colonies were typing by antisera. In the present work, all E.coli strains showed lactose fermentation (pink colonies) on MacConkey agar and/or VRBL agar medium and green metallic sheen colonies on EMB. Out of 400 chickens samples300 from imported chicks and 100 sample from local broiler chicken found 133 (44\%) was positive for E.coli from imported chicks and $75(75 \%)$ positive E.coli from local broiler chickens. Table (1) (Zhao et al., 2001) demonstrated that the incidence of $\mathrm{E}$. coli for imported chicks nearly similar to that observed in the present study. For example, the prevalence of E. coli in baby chicks was
(38.7\%). Interestingly, more recent investigations revealed much higher rates of E. coli for chicken $(68 \%)$ obtained by Kegodeet al., 2008. The current results showed that E.coli isolates were recovered in the highest rate from chickens showing symptoms of colisepticaemia, indicating the role of the organism as potentially important avian pathogen. These finding agreed with those obtained by Khalid (1990); Mukhopadhyaya and Mishra (1992), Sripoernomo et al., (1992) and Yun et al. (1997). E.coli was isolated from $52 \%$ of examined chicken almost similar percentages $47.3 \%$ in chickens were reported by Ramaswamyet al. (1982) and Barbour et al. (1985), who isolated E.coli from $40.4 \%$ of samples from colisepticaemia chickens. The incidence of E.coli in one day old living diseased chicks was $(58.3 \%)$ while in freshly dead chicks it was $(23.3 \%)$. The highest percentage of organ isolation was obtained from liver, it was about $21.6 \%$ from 300 isolate. The incidence of E.coli from local broiler chickens (over one week old) was $73 \%$ from living diseased chicken, while in freshly dead chicken it was $(83 \%)$. The highest percentage of organ isolation were obtained from bone marrow was about $30 \%$ from 100 sample table (2). On another hand Tapan et al., (2012) detected colibacillosis from different farms. the highest isolation rate of E.coli from yolk sac $(52.6 \%)$ and heart blood (38.4) in one day old -4week, and the highest percentage of E.coli isolation was from pericardial fluid (35.8\%) followed by heart blood (33.4\%) in older age (4-7 week). AbdElatif (2004) examined 150 samples taken from five broiler chicken revealed the isolation of E.coli with percentage of $78.7 \%$, where the isolation from apparently healthy chickens with percentage of $72.0 \%$ and clinically diseased chickens with percentage of $85.3 \%$, respectively. From the isolated E.coli, 208 strains recovered from different organs of chickens relieved that 158 strains can be serotyped serologically .and belonged to different serogroups. The most commonly detected E.coli serogroups 
were O44 (11.3\%), O158 (11.3\%), O125 (7.5\%), O103 (9.4\%), O63 (7.5\%), O91 $(8.8 \%)$, while 50 strain was un- typed. These results go hand to hand with the previous studies of Suwanichkul and Panigrahy (1988), Gross (1991) and Bosch et al. (1993), who reported that serogroups O44, O158, O114 and O91 were traditionally associated with colibacillosis in poultry table(4). By using disc diffusion method showed that E.coli isolate were resistant to ciprofloxacin about $12(40 \%)$, $14(46.6 \%)$ of E.coli isolate resistance to gentamycin. Also 16 (63.3\%) E.coli isolate were resistance to erythromycin antibiotic among 30 E.coli isolate. 16 (53.3\%) showed resistance to florfenicol antibiotic among 30 isolate in these study (table5) nearly similar result were detected by Jiang et al., (2011) about $44.4 \%$ of isolate were resistant to ciprofloxacin a among chicken E.coli strain in China .On other hand Wang et al. (2001) found that high rates of resistance to quinolones have been reported from different parts of the world. In China, for example, more than $50 \%$ of the clinical strains of E. coli isolated during 1997-1999 were resistant to ciprofloxacin .Also Xia et al. (2009) observed that 198 avian E.coli isolates from Shandong, China were resistant to enrofloxacin 99\%, ciprofloxacin100. Soufi (2009) recorded $2 \%$ resistance to gentamycin among fifty five E.coli isolate that disagree with our result while Makhol et al., (2011) demonstrated that $(100 \%)$ of all tested isolates of E.coli strains isolated from poultry were resistant to erythromycin. Also Xinet al., (2007) observed that about 29\% of E.coli isolate was resistance to florfenicol antibiotics in order to ensure the rational and effective use of these drugs. $\beta$ Lactam group (amxociline and ampicillin) showed 22(73.3\%) resistant and that was similar agree with Guerra et al. (2003) who was found resistance in $40 \%$ E.coli strains isolated and multi resistance in $32 \%$ of the strains. The present study detected most of isolates was resistance to tetracycline with percent $80 \%$ by disc diffusion as shown in table (5) which agree with 'Moon et al (2011) that studied the actual frequency of antimicrobial resistance in fecal Escherichia coli isolated from .One hundred and nine E.coli isolates were higher resistant to ampicillin (68.8\%) streptomycin (60.6\%), ciprofloxacin $(65.1 \%)$, and tetracycline (96.3\%). Chopra and Roberts, (2001) noticed the high rate of resistant to tetracycline was done due to inhibition bacterial protein synthesis by preventing attachment of t-RNA to ribosome.

Conclusion: Multidrug resistance among isolated E.coli which impair the poultry rearing and can affect the human health so antibiotics should be given after making sensitivity test to avoid misuse of drug as well as give in proper dose and recommended duration.

\section{REFERENCES}

AbdElatif, M.M. 2004. E.coli associated with swollen head syndrome in broiler chickens. Assiut Vet. Med. J., 50 (101):188-189.

Amara, A., Ziani, Z. ,Bouzoubaa, K. 1995. Antibioresistance of E.coli strains isolated in Morocco from chickens with colibacillosis. Vet. Microbiol., 43:325-330

Bandyopadhay, P.K., Dhawedkar, R.G. 1984. E.coli salpingoperitonitis in poultry. Indian Vet. J., 61:348-349.

Barbour, E.K., Nabbed, N. H., Al-Nakhli, H.M. 1985. Use of epidemiologic markers to identify the source of E. coli infections In Poultry. Am. J. Vet. Res., 46(4):989-91.

Barnes, J.H. 1994. Colibacillosis in poultry, Veterinary Practicum, Continuing Education for the Veterinary profession, published as Educational Grant from Pfizer Animal Health

Blanco, J.E., Blanco, M., Mora, A., Jansen, W.H., Garcia, V.V., Azquez, M.L., Blanco, J. 1998. Serotypes of E. coli isolated from septicemia in chickens in Galicia (northwest Spain). Vet. Microbiol., 61(3):229-235. 
Bosch, J.F., Hendricks, J.H., Gladigan, I., Willimes, H.M., Storm, PK., Graaf, F.K., Van-den-Bosch, Graaf, F.K. 1993. Identification of fimbriae on chicken E.coli strains. Infect. Immune, 61(3):800-806.

Chopra, I., Roberts, M. 2001. Tetracycline antibiotics: mode of action, applications, molecular biology and epidemiology of bacterial resistance. Microbiol. Mol. Biol. Rev., 65:232260.

Cruickshank, H., Duguid, J.P., Marmon, B.P., Swain, R.H.A. 1975. Medical Microbiology. The practice of Medical Microbiology, $12^{\text {th }}$ Ed. Churchill Livingstone, Edinburgh. London and New York.

Cloud, S.S., Rosenberger, J.K., Fries, P.A., Wilson, R.A., Wilson, R.A., Odor, E.M. 1985.In vitro and in vivo characterization of avian E. coli 1serotypes, metabolic activity and antibiotic sensitivity. Avian Dis., 29(4):1084-1093

Edwards, R., Ewing, H. 1972. Identification of Enterobacteriacae. Minneapolis, Burgess Publishing Co., PP. 709.

Ewers, C., Janssen, T., Wieler, L.H. 2003. Avian pathogenic E.coli (APEC). Berl. Munch. Tierarztl. Wschrschr. 116(9-10):381-95.

Gross, W.B. 1991. Colibacillosis diseases of poultry, 9thEd: pp. 38-144 Editors Calnek, B.W. et al. Lowa State Univ . Press, Ames. Iowa State Univ.

Guerra, B., Junker, E., Schroeter, A., Malorny, B., Lehmann, S., Helmuth, R. 2003. Phenotypic and genotypic characterization of antimicrobial resistance in German Escherichia coli isolates from cattle, swine and poultry. J. Antimicrob. Chemother., 52(3):489-492.

Jiang, H., Lü, D., Chen, Z., Wang, X., Chen, J., Liu, Y., Liao, X., Liu, J., Zeng, Z. 2011. High prevalence and widespread distribution of multiresistant Escherichia coli isolates in pigs and poultry in China. Vet. J., 187: 99-103

Khalid, A.M. 1990. Studies on natural and experimental E.coli infection in chickens. J. Egypt. Vet Med. Ass. 50 (3):379-389

Kegode, R.B., Doetkott, D. K., Khaitsa, M. L., Wesley, M. L. 2008. Occurrence of Campylobacter species, Salmonella species and generic Escherichia coli in meat products from retail outlets in the Fargo metropolitan area, J. Food Safety 28:111-125.

Kaul, L., Kaul, L.P., Shah, N.M. 1992. An outbreak of colibacillosis in chicks at an organized poultry farm under semiarid zone of north Gujarat. Indian Vet. J., 69:373-374.

Makhol, B. M., Habreh, N., Sakural, K. 2011. Antibiotic resistance of E.coli isolated from poultry in Syria. Assiut Vet. Med. J. 57(128):265-275.

'Moon Ho Jang, 'Jae Keun Cho, iDongMiKwak, 'Gil-Jae Cho, Young Ju Lee 2011.Antimicrobial Resistance and Resistance Gene Determinants of Fecal Escherichia coli Isolated from Chicken. Korea Journal of Animal and Veterinary Advances 10(24): 3308-3311.

Mukhopadhyaya, B.N., Mishra, S. K. 1992. Incidence of colibacillosis in chicks in some poultry of west Bengal. Indian J. Poult. Sci., 27(2):103-107

NCCLS; National Committee for Clinical Standers. 2002. Methods for antimicrobial susceptibility testing of anaerobic bacteria, 2nd Ed NCCLS document M11-T2 Villanova. PA 19085. USA.

Quinn, P.J., Markey, B.K., Carter, M.E., Donnelly, W.J.C., Leonard, F.C. 2002. Veterinary microbiology and microbial diseases.1st Iowa State University Press Blackwell Science.

Ramaswamy, V., Jayarman, M.S., Venugopalan, A.T., Balaprakasam, R.A. 1982. Serotypes of E.coli strains isolated from pathological condition 
of poultry. J. Vet. Sci. Anim. Husb., 11(3):395-398.

Sripoernomo, N., Suterma, S.L., Jeanuri, M., Iskanda, R. 1992. Colibacillosis in poultry in Indonesia. Isolation and serotyping of E.coli from Poultry farms in java and Bali. Penyakit. Henan, 24(43):33-38.

Soufi, L., Abbassi, M.S., Saenz, Y.,Vinué, L., Somalo, S., Zarazaga, M., Abbas, A., et al. 2009. Prevalence and diversity of integrons and associated resistance genes in E.coli isolates from poultry meat in Tunisia. Foodborne. Pathog. Dis. 6(9):10671073

Suwanichkul, A., Panigrahy, H. 1988. Diversity of piles subunits of E.coli isolated from avian species. Avian Dis., 32(4):822-825

Swayne, D.E, Glisson, J.R., Jackwood, M.W, Pearson, J.E., Reed, W.M. 1998. E.coli a laboratory manual for the isolation and identification of avian pathogens, fourth edition. Am. Assoc. Avian path

Tapan, K.S., Lakshman, S., Laxmi, N., Sarangi, S., Kumar, P., Hemant, K. P. 2012. Prevalence, Isolation, Characterization and Antibiogram Study of Pathogenic Escherichia coli from Different Poultry Farms of Odisha. Journal of Advanced Veterinary Research 2:169-17

Wang, H., Dzinkfox, J.L., chen, M., levy, S.B. 2001. Genetic characterization of highly fluoroquinolone resistant clinical Escherichia coli strains from China: Role of acrR Mutations. Antimicrob. Agents Chemotherapy. 24(5):1515-1521.

Xia, L., Li, L., Wu, C., Liu, Y., Tao, X., et al. 2009. A survey of plasmid mediated fluoroquinolone resistance genes from Escherichia coli isolates and their dissemination in Shandong, China. Foodborne Path. Dis., 20090378.

Xin-Sheng, Li., Gui-Qin Wang, XiangDang Du, et al. 2007. Antimicrobial susceptibility and molecular detection of chloramphenicol and florfenicol resistance among Escherichia coli isolates from diseased chickens .Department of Pharmacology and Toxicology, College of Veterinary Medicine, China Agricultural University, Beijing 100094, P.R. China

Yun, S.F., Lan, Z.R., Wang, W.W., Zheng, M.A., Chai, B.X. 1997. Characterization of avian E.coli in Jiangsu. Act Agriculture Shanghai, 13(4):7-10.

Zhao, C., Ge, B., DeVillena, J., Sudler, R., Yeh, E., et al. 2001. Prevalence of Campylobacter spp., Escherichia coli, and Salmonella serovars in retail chicken, turkey, pork, and beef from the Greater Washington, D.C., area, Appl. Environ. Microbiol. 67:54315436. 